\title{
Nitric oxide synthase gene transfer inhibits biological features of bypass graft disease in the human saphenous vein
}

\author{
Felix C. Tanner, MD \\ Thomas Largiadèr, $M D^{b}$ \\ Helen Greutert ${ }^{\mathrm{a}}$ \\ Zhihong Yang, $\mathrm{MD}^{\mathrm{C}}$ \\ Thomas F. Lüscher, MD, FACC ${ }^{b}$
}

From Cardiovascular Research, Clinic for Cardiovascular Surgery and Department of Clinical Research, ${ }^{\text {a }}$ University Hospital, Bern, Switzerland, Cardiovascular Research, Physiology Institute, ${ }^{\mathrm{b}}$ University Zürich-Irchel and Division of Cardiology, University Hospital, Zürich, Switzerland, and Physiology Institute, ${ }^{\mathrm{c}}$ University of Fribourg, Fribourg, Switzerland.

F.C.T. and T.L. contributed equally to this work.

Supported by the Swiss National Science Foundation (grants 31-47119.96 and 32-51069.97), the Swiss Heart Foundation, the Hartmann Müller Foundation, the Schweizerische Rentenanstalt, and the Postgraduate Course of the University of Zürich.

Received for publication Nov 29, 2002; revisions requested Feb 10, 2003; revisions received July 2, 2003; accepted for publication July 30, 2003.

Address for reprints: Thomas F. Lüscher, MD, FACC, Cardiology, University Hospital, Rämistrasse 100, CH-8091 Zürich, Switzerland (E-mail: cardiotfl@gmx.ch).

J Thorac Cardiovasc Surg 2004;127:20-6

$0022-5223 / \$ 30.00$

Copyright () 2004 by The American Association for Thoracic Surgery

doi:10.1016/j.jtcvs.2003.07.021
Background: Bypass graft disease is related to proliferation and migration of vascular smooth muscle cells and to platelet activation with thrombus formation. Nitric oxide inhibits these biological responses; it has never been demonstrated, however, whether this occurs in intact human vascular tissue after endothelial nitric oxide synthase gene transfer.

Methods: We examined whether endothelial nitric oxide synthase overexpression inhibits biological features of bypass graft disease in saphenous vein tissue.

Results: The nitric oxide donor diethylenetriamineNONOate inhibited proliferation $(P<.001)$ and migration $(P<.001)$ of human saphenous vein vascular smooth muscle cells in response to $20 \%$ serum in a concentration-dependent manner. A similar effect on proliferation $(P<.05)$ and migration $(P<.05)$ without any cytotoxicity was observed after adenoviral endothelial nitric oxide synthase transfection. Staining of saphenous vein tissue for placental alkaline phosphatase demonstrated that adenoviral transfection was efficient. Consistent with this observation, endothelial nitric oxide synthase protein expression and nitric oxide release were enhanced in transfected tissue. Further, endothelial nitric oxide synthase overexpression inhibited vascular smooth muscle cell outgrowth from saphenous vein explants over 21 days; $48 \% \pm 12 \%$ of explants exhibited outgrowth after treatment with endothelial nitric oxide synthase adenovirus as compared with $69 \% \pm 10 \%$ in those infected with control adenovirus and 90\% $\pm 5 \%$ in uninfected tissue $(P<$ .05). Similarly, platelet adhesion to human saphenous vein tissue was inhibited by endothelial nitric oxide synthase overexpression; adhesion was reduced in segments infected with endothelial nitric oxide synthase adenovirus $(58 \% \pm 6 \%)$ as compared with those infected with control adenovirus $(107 \% \pm 8 \%)$ or uninfected saphenous vein $(100 \% ; P<.05)$.

Conclusions: These data demonstrate that endothelial nitric oxide synthase gene transfer inhibits biological features of bypass graft disease in intact human saphenous vein tissue. Therefore, endothelial nitric oxide synthase transfection represents a promising gene transfer approach to prevent venous bypass graft disease.

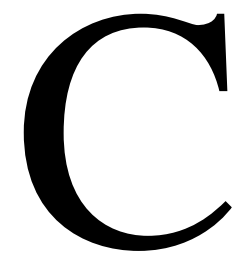

oronary artery disease is the most common cause of morbidity and mortality in Western countries. ${ }^{1}$ Treatment options include drugs, balloon angioplasty, and coronary artery bypass graft surgery. Coronary artery bypass graft surgery reduces both symptoms and mortality, particularly in patients with severe disease. ${ }^{2}$ It is performed with arterial grafts (most commonly the internal thoracic artery) or venous conduits (the saphenous vein; SV). Whereas internal thoracic 
artery grafts have excellent long-term patency, SV grafts are prone to early thrombotic occlusion and, within several years after implantation, to bypass graft disease. ${ }^{3}$ Acute thrombotic occlusion of SV grafts occurs less frequently since the introduction of platelet inhibitors for treating these patients. ${ }^{4}$ Bypass graft disease, however, remains a significant clinical problem, because approximately half of the venous grafts occlude within 10 years. ${ }^{5}$

The mechanisms of bypass graft disease include (1) proliferation and migration of vascular smooth muscle cells (VSMC), leading to neointima formation and vascular remodeling, and (2) platelet activation with thrombus formation. ${ }^{6}$ Because veins are not well adapted to the arterial circulation, which is characterized by high pressure and pulsatile flow, a promising strategy for the prevention of bypass graft disease consists of modifying the biological properties of the vessel by gene transfer. A candidate gene in this context is endothelial nitric oxide synthase (eNOS), because SVs exhibit a lower expression of eNOS, a reduced basal release of nitric oxide (NO), and less pronounced endothelium-dependent relaxation as compared with arteries. ${ }^{7}$ In contrast to eNOS, the inducible isoform of nitric oxide synthase (NOS) is upregulated in SV bypass grafts and may delay the development of graft disease. ${ }^{8}$ Indeed, NO not only is a vasodilator, but also inhibits platelet aggregation, as well as the proliferation and migration of cultured VSMC. ${ }^{9}$ Therefore, we investigated whether eNOS overexpression inhibits these processes in human SV tissue segments.

\section{Methods}

\section{Recombinant Adenovirus}

An adenoviral vector for expression of human placental alkaline phosphatase (AdhpAP) and a control virus without transgene $(\mathrm{Ad} \Delta \mathrm{E} 1)$ were derived from Ad5 sub360 and prepared as previously described. ${ }^{10} \mathrm{~A}$ similar virus for expression of endothelial NOS (AdeNOS) and the respective control virus were provided by Dr Stefan Janssens, Leuven, Belgium. These viruses were derived from Ad5 dL309 and were thus slightly different from Ad5 sub360. ${ }^{11}$ However, comparison of the effect of both control viruses on VSMC proliferation did not show any difference $(\mathrm{n}=$ 5; data not shown). Therefore, for the sake of clarity, both control viruses are called $\mathrm{Ad} \Delta \mathrm{E} 1$. The titer of purified viruses was determined by plaque assay on 293 cells by using an adsorption time of 24 hours and counting the number of plaques on day 12 after infection. ${ }^{12}$ Viral titers ranged from $2 \times 10^{10}$ to $2 \times 10^{11} \mathrm{pfu} / \mathrm{mL}$ for all preparations. The titer of wild-type virus in the purified preparations was determined by plaque assay on A549 cells by using the same conditions and was $<1$ in $10^{9} \mathrm{pfu} / \mathrm{mL}$ for all preparations.

Cell Culture, Tissue Culture, and Explant Preparation SV segments were obtained from human donors undergoing coronary bypass surgery through institutional consent. Vascular explants were prepared as previously described. ${ }^{13}$ Outgrowth of
VSMC from explants was observed for 21 days. For isolation of VSMC, explants were trypsinized, the cells were maintained in Dulbecco's modified Eagle's medium (DMEM) with 20\% fetal calf serum (FCS; Gibco BRL, Life Technologies, Inc, Rockville, $\mathrm{Md}$ ), characterized by immunofluorescent staining for smooth muscle $\alpha$-actin, and used between passage 2 and $10^{13} ; 293$ cells and A549 cells were obtained from the American Type Culture Collection (Manassas, Va) and cultured as recommended.

\section{Transfection}

VSMC were transfected at a multiplicity of infection of $1000 \mathrm{pfu}$ per cell; this resulted in $99 \%$ transfected cells $(n=4$; data not shown). Cytotoxicity was assessed by trypan blue staining as previously described. ${ }^{14}$ Tissue segments were incubated with a viral titer of $1 \times 10^{9} \mathrm{pfu} / \mathrm{mL}$ for 2 hours at $37^{\circ} \mathrm{C}$ and then kept in DMEM with $20 \%$ FCS for an additional 48 hours. Immunohistochemical staining for von Willebrand factor revealed that the endothelial layer was not fully maintained in the isolated SV tissue under control conditions, and this is consistent with published observations. ${ }^{15}$ However, transfection and incubation did not affect the morphologic integrity of the remaining endothelial layer (n $=4$; data not shown). Transfection efficiency was analyzed by using AdhpAP and determined by staining with NBT/BCIP (nitroblue tetrazolium chloride/5-bromo-4-chloro-3-indolylphosphate p-toluidine; Invitrogen) as previously described. ${ }^{16}$ Stained tissue segments were observed under a stereo microscope (Wild Leitz, Heerbrugg, Switzerland) at a magnification of $30 \times$.

\section{Proliferation}

VSMC were seeded at a density of 10,000 cells per $35-\mathrm{mm}$ dish and cultured for 24 hours, resulting in random proliferation at the beginning of treatment. The cells were treated with the NO donor diethylenetriamineNONOate (DETANO; $10^{-5}$ to $10^{-3} \mathrm{~mol} / \mathrm{L}$; Alexis, Läufelfingen, Switzerland) because it has a half-life of 27 hours and releases NO according to first-order kinetics. ${ }^{14}$ The cells were maintained in DMEM with 20\% FCS, media were changed every day, and fresh DETANO was added after every media change. Cell number was determined every other day for up to 4 days by using a hematocytometer. An analogous protocol was used for transfected VSMC, which were maintained in normal media containing 20\% FCS for 48 hours after transfection. Cell-cycle distribution was determined by propidium iodide staining and fluorescence-activated cell sorting analysis as previously described. ${ }^{14}$

\section{Migration}

VSMC were seeded at a density of 250,000 cells per $150-\mathrm{mm}$ dish and cultured for 24 hours before DETANO treatment. The cells were maintained in DMEM with 20\% FCS for 48 hours, media were changed every day, and fresh DETANO was added after every media change. The cells were harvested for analysis of migration in response to 20\% FCS in the presence of DETANO in a 2-chamber system (Neuroprobe Inc., Cabin John, Md) as previously described. ${ }^{17}$ The number of migrated cells was determined by staining (Diff-Quik; Dade Diagnostics Inc., Aguada, Puerto Rico) and counting the cells at $400 \times$ magnification on 4 random microscopic fields per group. ${ }^{17}$ An analogous protocol was used for transfected VSMC, which were maintained in normal media 
A

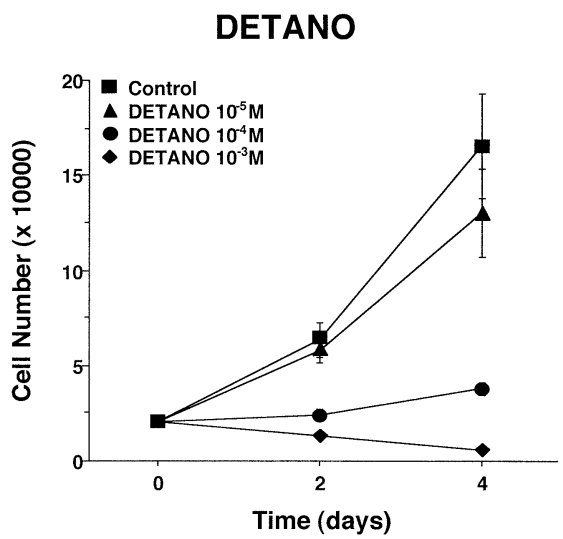

B

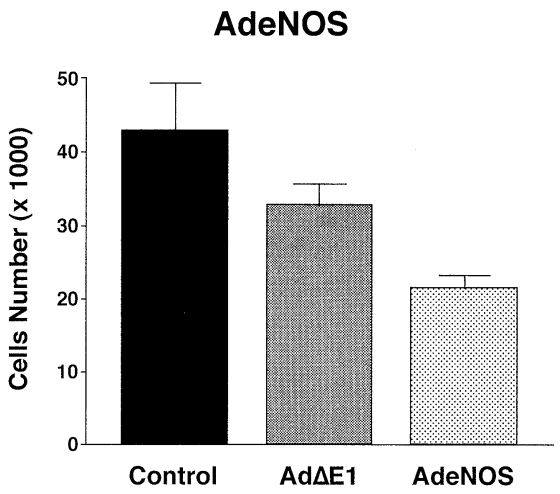

Figure 1. A, Effect of the NO donor diethylenetriamineNONOate (DETANO) on proliferation of human saphenous vein vascular smooth muscle cells (VSMC) to $20 \%$ fetal calf serum (FCS): FCS increased the cell number within 4 days from $20.859 \times 10^{3} \pm$ $1.336 \times 10^{3}$ to $165.406 \times 10^{3} \pm 27.649 \times 10^{3}$; DETANO reduced it to $130.125 \times 10^{3} \pm 23.029 \times 10^{3}\left(10^{-5} \mathrm{~mol} / \mathrm{L}\right), 37.703 \times 10^{3} \pm 3.078$ $\times 10^{3}\left(10^{-4} \mathrm{~mol} / \mathrm{L}\right)$, and $5.750 \times 10^{3} \pm 0.793 \times 10^{3}\left(10^{-3} \mathrm{~mol} / \mathrm{L} ; P\right.$ $<.001$ ). B, Effect of endothelial nitric oxide synthase (eNOS) overexpression on proliferation of human saphenous vein VSMC to $20 \%$ FCS: FCS increased the cell number within 4 days from $14.625 \times 10^{3} \pm 1.102 \times 10^{3}$ to $45.694 \times 10^{3} \pm 7.070 \times 10^{3}$ under control conditions, $34.938 \times 10^{3} \pm 3.038 \times 10^{3}$ with control adenovirus $(\mathrm{Ad} \Delta \mathrm{E} 1)$, and $22.831 \times 10^{3} \pm 1.921 \times 10^{3}$ with NOS adenovirus (AdeNOS; $\boldsymbol{P}<.05$ vs control).

containing 20\% FCS for 48 hours after transfection. Cell attachment was assessed by seeding 40,000 cells and determining the number of cells sticking to the culture dish after an incubation time of 5 hours. ${ }^{18}$

\section{Platelet Adherence}

Venous blood was obtained from healthy human donors who had not taken any medication within the last 10 days. Platelets were collected as previously described except for the final washing solution, which contained $0.15 \mathrm{~mol} / \mathrm{L} \mathrm{NaCl}, 1 \mathrm{mmol} / \mathrm{L}$ ethylenediaminetetraacetic acid, and $0.01 \mathrm{~mol} / \mathrm{L}$ HEPES (EHS buffer; $\mathrm{pH}$ 7.6). ${ }^{19}$ Washed platelets were equilibrated in EHS buffer at $4^{\circ} \mathrm{C}$ for 10 minutes, sodium periodate was added to the final 1 $\mathrm{mmol} / \mathrm{L}$, and platelets were centrifuged at $800 \mathrm{~g}$ and resuspended in EHS buffer at a concentration of $2.5 \times 10^{8} / \mathrm{mL}$. [ $\left.{ }^{3} \mathrm{H}\right]$ Sodium borohydride $0.1 \mathrm{mCi}$ was added and incubated for 5 minutes. Labeled platelets were centrifuged, washed 3 times, and resuspended in EHS buffer containing 1\% FCS. SV segments were opened longitudinally, fixed with the intimal face up, and incubated with labeled platelets $\left(2.5 \times 10^{8} / \mathrm{mL}\right)$ for 30 minutes. After washout, the number of adhering platelets was determined by using a beta counter.

\section{Western Blot Analysis}

Western blot analysis was performed on whole-cell lysates as previously described. ${ }^{20} \mathrm{~A}$ total of $60 \mu \mathrm{g}$ of protein was loaded per lane, resolved by sodium dodecyl sulfate-polyacrylamide gel electrophoresis under reducing conditions, blotted onto polyvinylidene difluoride membranes, and analyzed by chemiluminescence (Amersham, Piscataway, NJ). Equal loading of proteins was controlled for by staining with Ponceau S.

\section{NO Release}

After transfection, tissue pieces were kept in DMEM with $20 \%$ FCS at $37^{\circ} \mathrm{C}$ for 48 hours. NO release was stimulated by $10^{-5}$ $\mathrm{mol} / \mathrm{L}$ calcium ionophore A23187, a concentration that fully activates eNOS. NO was measured by a porphyrinic microsensor as previously described. $^{21}$

\section{Statistics}

Results represent the mean value of 5 experiments as indicated in the text. Data are expressed as mean \pm SEM, and statistical comparisons were performed by using Student $t$ tests for unpaired observations or analysis of variance with Dunnett $t$-test correction whenever appropriate.

\section{Results}

\section{Proliferation}

DETANO inhibited VSMC proliferation in response to $20 \%$ FCS in a concentration-dependent manner. FCS increased the cell number over 4 days from $20.859 \times 10^{3} \pm 1.336 \times$ $10^{3}$ to $165.406 \times 10^{3} \pm 27.649 \times 10^{3}$. DETANO reduced this effect to $130.125 \times 10^{3} \pm 23.029 \times 10^{3}$ at $10^{-5} \mathrm{~mol} / \mathrm{L}$, $37.703 \times 10^{3} \pm 3.078 \times 10^{3}$ at $10^{-4} \mathrm{~mol} / \mathrm{L}$, and $5.750 \times$ $10^{3} \pm 0.793 \times 10^{3}$ at $10^{-3} \mathrm{~mol} / \mathrm{L}(P<.001$ vs control; Figure 1,A). Adenoviral transfection of eNOS complementary DNA (cDNA) inhibited VSMC proliferation in response to $20 \%$ FCS. FCS increased the cell number over 2 days from $14.625 \times 10^{3} \pm 1.102 \times 10^{3}$ to $45.694 \times 10^{3} \pm$ $7.070 \times 10^{3}$ under control conditions as compared with $34.938 \times 10^{3} \pm 3.038 \times 10^{3}$ with the control adenovirus $(\mathrm{Ad} \Delta \mathrm{E} 1 ; P=.32$ vs control $)$ and $22.831 \times 10^{3} \pm 1.921 \times$ $10^{3}$ with the NOS adenovirus (AdeNOS; $P<.05$ vs control and $P<.05$ vs $\mathrm{Ad} \Delta \mathrm{E} 1$; Figure $1, B)$. Trypan blue exclusion was identical in transfected versus control VSMC (control: $1.35 \% \pm 0.88 \%$ trypan blue-positive cells; $\mathrm{Ad} \Delta \mathrm{E} 1: 1.57 \%$ $\pm 1.02 \%$; AdeNOS: $1.57 \% \pm 0.92 \% ; \mathrm{n}=4 ; P=.56)$. Thus, no toxic effect of AdeNOS was involved. Consistent 
with this observation, a shift in cell-cycle distribution occurred after eNOS transfection (control, $75 \%$ of cells in $\mathrm{G}_{0} / \mathrm{G}_{1}$ phase; Ad $\Delta \mathrm{E} 1,76 \%$; and AdeNOS, $81 \%$; $\mathrm{n}=4$ ).

\section{Migration}

DETANO inhibited VSMC migration in response to $20 \%$ FCS in a concentration-dependent manner. FCS increased the number of migrated cells within 5 hours from $4.8 \pm 2.7$ to $26.4 \pm 2.1$. DETANO reduced this effect to $20.8 \pm 2.2$ at $10^{-5} \mathrm{~mol} / \mathrm{L}, 14.0 \pm 1.6$ at $10^{-4} \mathrm{~mol} / \mathrm{L}$, and $9.6 \pm 1.4$ at $10^{-3} \mathrm{~mol} / \mathrm{L}(P<.001$ vs control; Figure $2, A)$. Adenoviral transfection of eNOS cDNA inhibited VSMC migration in response to $20 \%$ FCS. FCS increased the number of migrated cells within 5 hours from $4.5 \pm 1.8$ to $60.3 \pm 6.0$ under control conditions as compared with $46.3 \pm 6.0$ with the control adenovirus (Ad $\Delta \mathrm{E} 1 ; P=.48$ vs control) and $35.5 \pm 6.0$ with the NOS adenovirus (AdeNOS; $P<.05$ vs control and $P=.27$ vs AddE1; Figure 2, B). Cell attachment was not affected by eNOS transfection (control: $20.031 \times 10^{3} \pm 0.890 \times 10^{3}$ attached cells per 6-well dish; $\operatorname{Ad} \Delta \mathrm{E} 1: 20.344 \times 10^{3} \pm 0.756 \times 10^{3}$; AdeNOS: $19.344 \times$ $\left.10^{3} \pm 0.790 \times 10^{3} ; P=.71\right)$.

\section{NO Release}

Adenoviral transfection of human SV was assessed by overexpression of human placental alkaline phosphatase (hpAP). NBT/BCIP staining revealed the presence of functional hpAP in SV transfected with hpAP adenovirus (AdhpAP), but not with control adenovirus (Ad $\Delta E 1)$ or in transinfected vessels (Figure 3,A). Expression of eNOS in human SV after adenoviral transfection was examined by Western blot analysis and demonstrated the presence of eNOS protein in SV transfected with eNOS adenovirus (AdeNOS), but not with control adenovirus (Ad $\Delta \mathrm{E} 1)$ or in untransfected vessels (Figure 3,B). NO release of human SV on stimulation with the calcium ionophore A23187 reached $339 \% \pm 74 \%$ of control after eNOS transfection, whereas it was $65 \% \pm 13 \%$ of control after treatment with $\operatorname{Ad} \Delta$ E1 $(P<.01$ for control vs AdeNOS; $P<.005$ for $\operatorname{Ad} \Delta \mathrm{E} 1$ vs AdeNOS; $P=.22$ for control vs $\operatorname{Ad} \Delta \mathrm{E} 1)$. Thus, NO release increased approximately 3 -fold after eNOS transfection as compared with control conditions (Figure 3, C).

\section{Explant Outgrowth}

The effect of eNOS overexpression on explant outgrowth from human SV was determined for an observation period of 21 days. A total of $90 \% \pm 5 \%$ of explants exhibited outgrowth of VSMC in uninfected SV as compared with $69 \% \pm 10 \%$ in those transfected with control adenovirus $(\mathrm{Ad} \triangle \mathrm{E} 1)$ and $47 \% \pm 12 \%$ in those transfected with eNOS adenovirus (AdeNOS; $P<.05$ vs control; Figure $4, A$ ).
A

DETANO

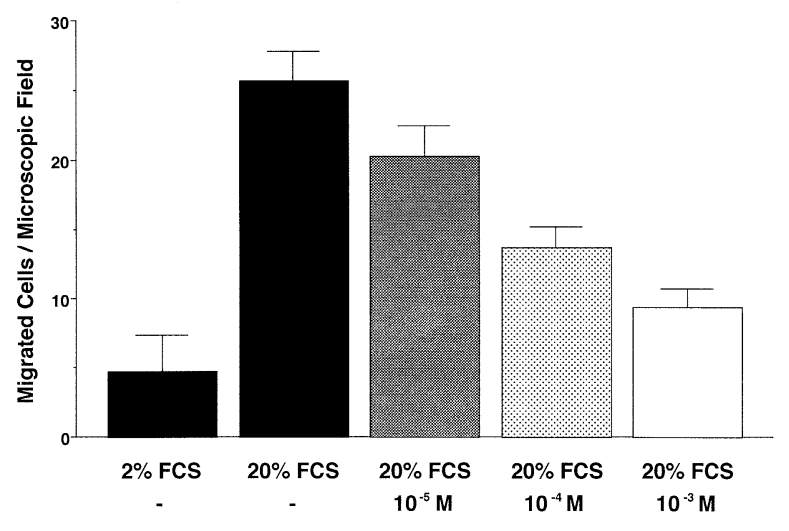

B

AdeNOS

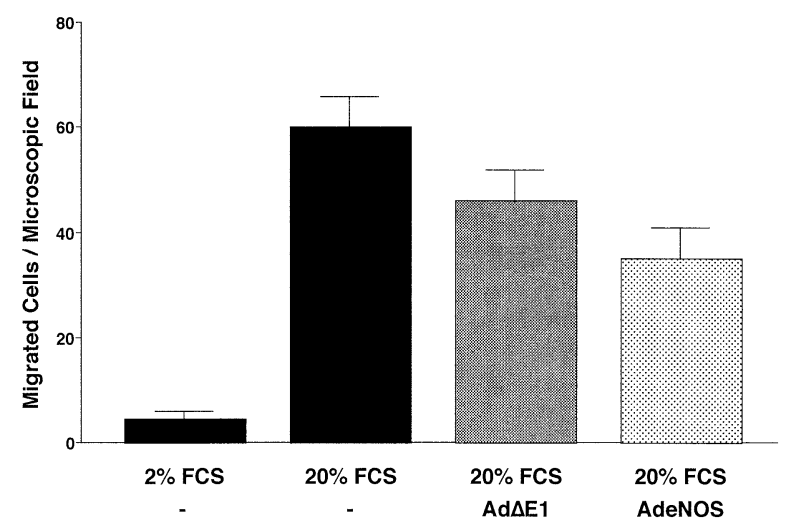

Figure 2. A, Effect of the NO donor diethylenetriamineNONOate (DETANO) on migration of human saphenous vein vascular smooth muscle cells (VSMC) to $20 \%$ fetal calf serum (FCS): FCS increased the migrating cell number within 5 hours from $4.8 \pm 2.7$ to $26.4 \pm 2.1$; DETANO reduced it to $20.8 \pm 2.2\left(10^{-5} \mathrm{~mol} / \mathrm{L}\right), 14.0$ $\pm 1.6\left(10^{-4} \mathrm{~mol} / \mathrm{L}\right)$, and $9.6 \pm 1.4\left(10^{-3} \mathrm{~mol} / \mathrm{L} ; P<.001\right)$. B, Effect of endothelial nitric oxide synthase (eNOS) overexpression on migration of human saphenous vein VSMC to $20 \%$ FCS: FCS increased the migrating cell number within 5 hours from $4.5 \pm 1.8$ to $60.3 \pm 6.0$ under control conditions, $46.3 \pm 6.0$ with control adenovirus (Ad $\Delta E 1$ ), and $35.5 \pm 6.0$ with NOS adenovirus (AdeNOS; $P<.05$ vs control).

\section{Platelet Adherence}

The effect of eNOS overexpression on platelet adherence to human SV was analyzed with ${ }^{3} \mathrm{H}$-labeled platelets and SV segments in organ culture. Platelet adherence was reduced in SV transfected with AdeNOS $(58 \% \pm 6 \%)$ as compared with those transfected with control adenovirus (Ad $\Delta \mathrm{E} 1$; $107 \% \pm 8 \%)$ or untransfected SV $(100 \% ; P<.05$ vs control; Figure $4, B)$. The effect of eNOS transfection on platelet adherence was inhibited by the competitive inhibitor of eNOS, $N$-nitro-L-arginine methyl ester $(90 \% \pm 3 \%)$. 
A
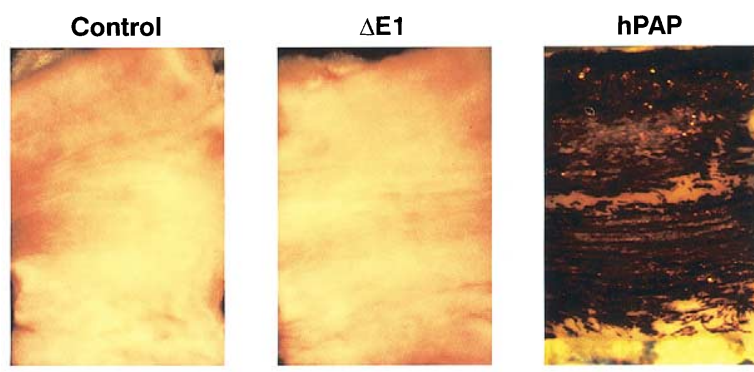

B Control $\Delta \mathrm{E} 1$ eNOS

C
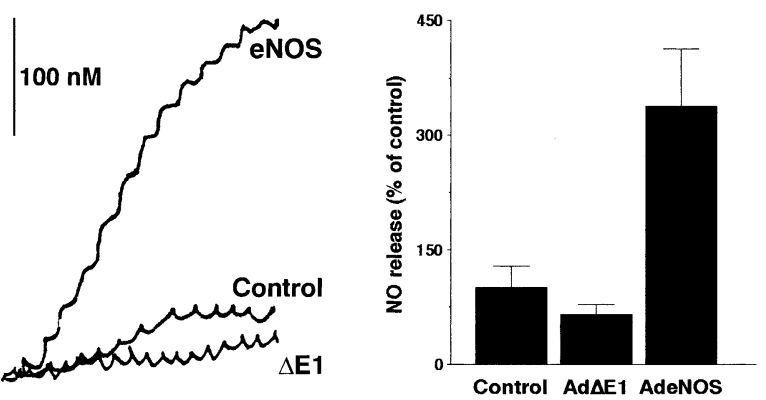

Figure 3. A, Expression of human placental alkaline phosphatase ( $h P A P)$ in human saphenous vein (SV) after adenoviral transfection: NBT/BCIP staining shows functional hPAP in SV transfected with hPAP adenovirus (AdhpAP), but not with control adenovirus (Ad $\Delta E 1$ ) or in untransfected vessels. B, Expression of endothelial nitric oxide synthase (eNOS) in human SV after adenoviral transfection: Western blot analysis shows eNOS protein in SV transfected with eNOS adenovirus (AdeNOS), but not with control adenovirus (Ad $\Delta E 1$ ) or in untransfected vessels. C, Release of NO from human SV after adenoviral transfection: direct NO measurement by porphyrinic microsensor revealed a threefold increase in NO release after transfection with eNOS adenovirus (AdeNOS) as compared with control adenovirus (Ad $\Delta E 1$ ) or untransfected vessels. Left panel, original recording; right panel, average values from 4 independent experiments $(P<.01$ for eNOS vs control).

\section{Discussion}

This study demonstrates that ex vivo eNOS gene transfer inhibits the biological features of bypass graft disease in intact human SV tissue segments. Indeed, adenoviral transfection of eNOS inhibited proliferation and migration of human SV VSMC, impaired VSMC outgrowth from SV explants, and reduced platelet adherence to SV segments. Hence, this study confirms and expands previous reports on transfection of human SV. ${ }^{22-24}$

The control adenovirus had some effect on the proliferation and migration of VSMC. Similar to our previous

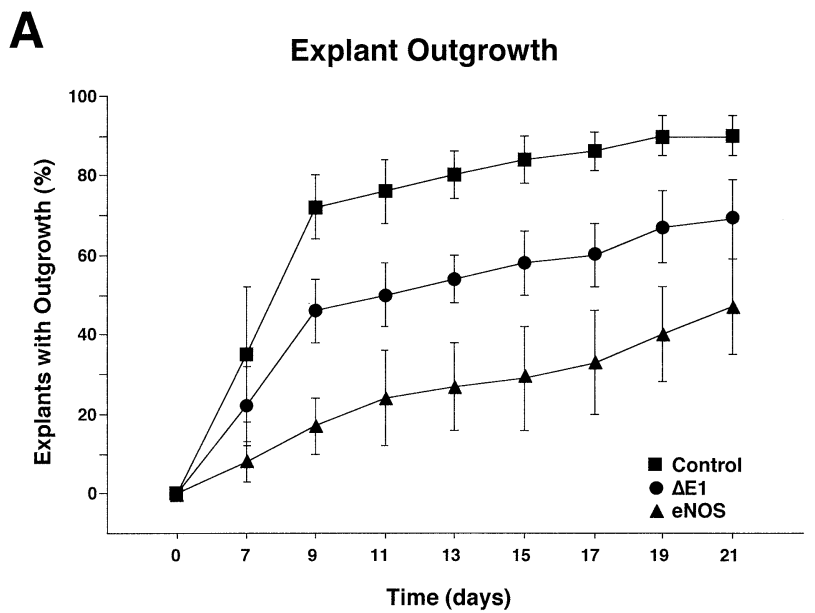

B

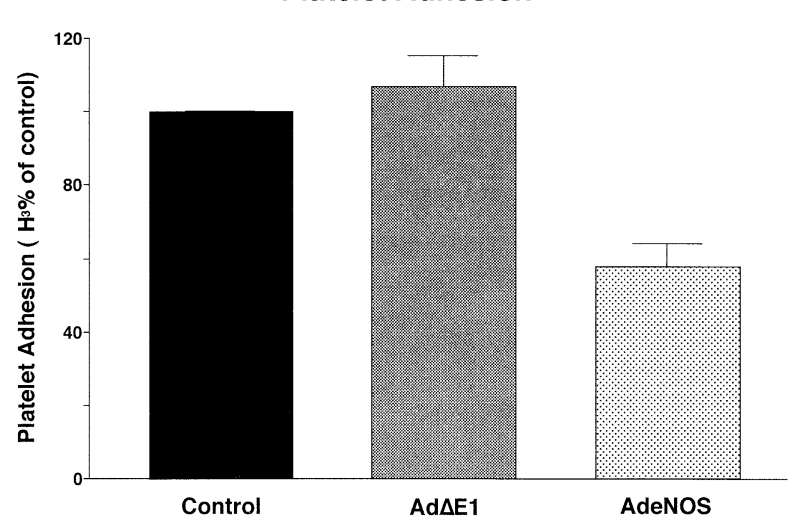

Figure 4. A, Effect of endothelial nitric oxide synthase (eNOS) overexpression on explant outgrowth from human saphenous vein (SV): after 21 days, $90 \%$ of explants exhibited outgrowth of vascular smooth muscle cells in untransfected SV as compared with $69 \%$ in those transfected with control adenovirus (Ad $\Delta \mathrm{E} 1$ ) and $48 \%$ with eNOS adenovirus (AdeNOS; $P<.05$ vs control). $B$, Effect of eNOS overexpression on platelet adhesion to human SV: platelet adhesion was reduced in SV transfected with eNOS adenovirus (AdeNOS; 57\%) as compared with those transfected with control adenovirus (Ad $\Delta E 1 ; 107 \%)$ or untransfected SV (100\%; $P<.05$ vs AdeNOS).

observations, a toxic effect leading to cell death is unlikely because trypan blue staining did not differ from control conditions. ${ }^{14}$ Further, an effect of the virus on expression of eNOS or inducible NOS can be excluded, because the control vector did not have any effect on $\mathrm{NO}$ formation as determined by the porphyrinic microsensor. However, even though cell death was not induced, it cannot be excluded that the nonspecific action of the virus may result in some degree of inflammation after the grafts are placed in the circulation.

In the first several months after coronary bypass graft operation, graft occlusion is related to thrombus formation 
that is due to vein graft injury and associated coronary artery disease with low blood flow in the vein graft. ${ }^{25-27}$ The low release of NO from SV endothelium on platelet aggregation may primarily be responsible for this high incidence of thrombotic events. Platelet deposition in vein grafts starts during surgery as soon as blood flow through the graft is initiated. ${ }^{26}$ Thus, antithrombotic therapy with platelet-inhibitory drugs is started perioperatively and indeed reduces the rate of early graft occlusion, albeit without preventing it. ${ }^{27}$ Because eNOS overexpression in SV tissue results in reduced platelet adhesion because of NO release, such a transfection would reduce the incidence of thrombotic events early after bypass graft implantation. However, gene expression requires several hours to reach a high level of recombinant protein in transfected cells; indeed, in vivo experiments revealed that maximal gene expression in a vessel occurs a few days after adenoviral transfection and declines to a low level within 3 or 4 weeks. ${ }^{28}$ Endothelial NOS overexpression would therefore certainly not replace platelet-inhibitory drugs perioperatively, but it may be combined with the latter in an effective manner, resulting in improved patency rates. Indeed, thrombotic occlusion of venous grafts still remains a significant clinical problem for several months after bypass. ${ }^{29}$

Platelet deposits, through the release of potent growth factors such as platelet-derived growth factor, contribute importantly to VSMC proliferation and migration and, in turn, graft stenosis. Thus, eNOS overexpression may have a beneficial effect on neointima formation in venous bypass grafts, because transfection of SV tissue with eNOS cDNA resulted in reduced platelet adhesion. Moreover, eNOS overexpression is likely to reduce neointima formation by a direct inhibitory effect on this phenomenon as well, because both proliferation and migration of SV VSMC, as well as SV explant outgrowth, were reduced under these conditions. Consistent with a specific inhibition of cell-cycle progression, eNOS transfection did not have any toxic effect on SV VSMC but induced a shift in cell-cycle distribution toward $\mathrm{G}_{1}$ phase. Indeed, NO inhibits VSMC proliferation by specifically changing the expression and activity of cell-cycle regulatory proteins leading to $G_{1}$ phase arrest. ${ }^{14}$ The inhibitory effect of eNOS transfection on migration was specific as well, because VSMC attachment was not affected. The inhibition of migration may be related to altered functioning of integrins or metalloproteinases. ${ }^{30}$ With currently available vectors, adenoviral transfection results in high expression levels, which are, however, maintained for only a few weeks; therefore, a pronounced and maintained effect on late graft occlusion cannot be expected with these vectors. However, these data may serve as proof of concept. Moreover, because neointima formation in venous bypass grafts is induced by platelet aggregation, with the release of cytokines promoting proliferation and migration of VSMC, the platelet-inhibitory effect of recombinant eNOS may still prove beneficial for late occlusion. Indeed, prevention of acute thrombosis in vein grafts markedly reduces subsequent neointima formation several months after operation. Moreover, new vectors may prove superior, once the principle of eNOS gene transfer is established by using such early-generation vectors.

Thus, adenoviral transfection of eNOS cDNA into human SV tissue ex vivo is effective and inhibits the biological features of bypass graft disease in the isolated tissue. Local overexpression of this gene may prove beneficial for both early and late graft occlusion, especially in combination with platelet-inhibitory drugs. This study indicates that clinical studies with transfection of eNOS cDNA for preventing human bypass graft disease should be performed in patients.

The adenovirus for expression of endothelial NOS (AdeNOS) and the respective control virus were provided by Dr Stefan Janssens, Leuven, Belgium.

\section{References}

1. Libby P. Inflammation in atherosclerosis. Nature. 2002;420:868-74.

2. Lawrie GM, Morris GC Jr, Earle N. Long-term results of coronary bypass surgery. Ann Surg. 1991;213:377-87.

3. Loop FD, Lytle BW, Cosgrove DM, Stewart RW, Goormastic M, Williams GW, et al. Influence of the internal mammary artery graft on 10-year survival and other cardiac events. N Engl J Med. 1986;314: 1-6.

4. Chesebro JH, Clements I, Fuster V, Elveback LR, Smith HC, Bardsley WT, et al. A platelet-inhibitor drug trial in coronary-artery bypass operations: benefit of perioperative dipyridamole and aspirin therapy on early postoperative vein-graft patency. $N$ Engl J Med. 1982;307: 73-8.

5. Lytle BW, Loop FD, Cosgrove DM, Ratliff NB, Easley K, Taylor PC. Long-term (5 to 12 years) serial studies of internal mammary artery and saphenous vein coronary bypass grafts. J Thorac Cardiovasc Surg. 1985;89:248-58.

6. Bulkley BH, Hutchins GM. Accelerated atherosclerosis: a morphological study in 97 saphenous vein grafts. Circulation. 1977;55:163-9.

7. Lüscher TF, Diederich D, Siebenmann R, Lehmann K, Stulz P, von Segesser L, et al. Difference between endothelium-dependent relaxations in arterial and in venous coronary bypass grafts. $N$ Engl J Med. 1988;319:462-7.

8. Dattilo JB, Dattilo MP, Spratt JA, Matsuura J, Yager DR, Makhoul RG. Inducible nitric oxide synthase expression in human vein grafts. Am J Surg. 1997;174:177-80.

9. Lüscher TF, Vanhoutte PM. The endothelium: modulator of cardiovascular function. Boca Raton (FL): CRC Press; 1990.

10. Ohno T, Gordon D, San H, Pompolij VJ, Imperiale MJ, Nabel GJ, et al. Gene therapy for vascular smooth muscle cell proliferation after arterial injury. Science. 1994;265:781-4.

11. Alcorn JL, Gao E, Chen Q, Smith ME, Gerard RD, Mendelson CR. Genomic elements involved in transcriptional regulation of the rabbit surfactant protein-A gene. Mol Endocrinol. 1993;7:1072-85.

12. Mittereder N, March KL, Trapnell BC. Evaluation of the concentration and bioactivity of adenovirus vectors for gene therapy. J Virol. 1996; 70:7498-509.

13. Yang Z, Oemar BS, Carrel T, Kipfer B, Julmy F, Lüscher TF. Different proliferative properties of smooth muscle cells of human arterial and venous bypass vessels: role of PDGF receptors, mitogen-activated protein kinase and cyclin-dependent kinase inhibitors. Circulation. 1998;97:181-7.

14. Tanner FC, Meyer P, Greutert H, Champion C, Nabel EG, Lüscher TF. 
Nitric oxide modulates expression of cell cycle regulatory proteins: a cytostatic strategy for inhibiting human vascular smooth muscle cell proliferation. Circulation. 2000;101:1982-9.

15. Tsui JC, Souza DS, Filbey D, Karlsson MG, Dashwood MR. Localization of nitric oxide synthase in saphenous vein grafts harvested with a novel 'no-touch' technique: potential role of nitric oxide contribution to improved early graft patency rates. J Vasc Surg. 2002;35:356-62.

16. Tanner FC, Carr DP, Nabel GJ, Nabel EG. Transfection of human endothelial cells. Cardiovasc Res. 1997;35:522-8.

17. Koyama N. Secretion of a potent new migration factor for smooth muscle cells (SMC) by cultured SMC. Atherosclerosis. 1991;86:219-26.

18. Diez-Juan A, Andres V. Coordinate control of proliferation and migration by the $\mathrm{p} 27 \mathrm{Kip} 1 / \mathrm{cyclin}$-dependent kinase/retinoblastoma pathway in vascular smooth muscle cells and fibroblasts. Circ Res. 2003; 92:402-10

19. Berndt MC, Phillips DR. Purification and preliminary physicochemical characterization of human platelet membrane glycoprotein V. J Biol Chem. 1981;256:59-65.

20. Tanner FC, Yang Z, Duckers E, Gordon D, Nabel GJ, Nabel EG. Expression of cyclin-dependent kinase inhibitors in vascular disease. Circ Res. 1998;82:396-403.

21. Tschudi MR, Barton M, Bersinger NA, Moreau P, Cosentino F, Noll $\mathrm{G}$, et al. Effect of age on kinetics of nitric oxide release in rat aorta and pulmonary artery. J Clin Invest. 1996;98:899-905.

22. Cable DG, O'Brien T, Schaff HV, Pompili VJ. Recombinant endothelial nitric oxide synthase-transduced human saphenous veins: gene therapy to augment nitric oxide production in bypass conduits. Circulation. 1997;96(9 suppl):II173-8.
23. Cable DG, Caccitolo JA, Caplice N, O'Brien T, Simari RD, Daly RC, et al. The role of gene therapy for intimal hyperplasia of bypass grafts. Circulation. 1999;100(9 suppl):II392-6.

24. Yu H, Kumar SR, Tang L, Terramani TT, Rowe VL, Wang Y, et al. Injury induced neointima formation and its inhibition by retrovirusmediated transfer of nitric oxide synthase gene in an in-vitro human saphenous vein culture model. Atherosclerosis. 2002;161:113-22.

25. Uni KK, Kottke BA, Titus JL, Frye RL, Wallace RB, Brown AL. Pathologic changes in aortocoronary saphenous vein grafts. Am J Cardiol. 1974;34:526-32.

26. Fuster V, Dewanjee MK, Kaye MP, Josa M, Metke MP, Chesebro JH. Noninvasive radioisotopic technique for detection of platelet deposition in coronary artery bypass grafts in dogs and its reduction with platelet inhibition. Circulation. 1979;60:1508-12.

27. Pfisterer M, Burkart F, Jockers G, Meyer B, Regenass S, Burckhardt $\mathrm{D}$, et al. Trial of low-dose aspirin plus dipyridamole vs. anticoagulants for prevention of aortocoronary vein graft occlusion. Lancet. 1989;2: $1-7$.

28. Nabel EG. Gene therapy for cardiovascular disease. Circulation. 1995; 91:541-8.

29. Chen L, Theroux P, Lesperance J, Shabani F, Thibault B, De Guise P. Angiographic features of vein grafts versus ungrafted coronary arteries in patients with unstable angina and previous bypass surgery. $J \mathrm{Am}$ Coll Cardiol. 1996;28:1493-9.

30. Gurjar MV, Sharma RV, Bhalla RC. eNOS gene transfer inhibits smooth muscle cell migration and MMP-2 and MMP-9 activity. Arterioscler Thromb Vasc Biol. 1999;19:2871-7. 